\title{
Circadian rhythm of serum cytidine deaminase in patients with rheumatoid arthritis during rest and exercise
}

\author{
P W THOMPSON ${ }^{1}$ I T JAMES, ${ }^{1}$ S WHEATCROFT ${ }^{2}$ R POWNALL ${ }^{3}$ AND \\ C G BARNES
}

From the ${ }^{1}$ Bone and Joint Research Unit, The London Hospital Medical College, London; the ${ }^{2}$ Departmen of Rheumatology, The London Hospital, London; and the ${ }^{3}$ Medical Science Research Department, Boot. Company PLC, Nottingham

SUMMARY Circadian rhythm of serum cytidine deaminase and $C$ reactive protein was assesse $\delta^{N}$ in 11 inpatients with rheumatoid arthritis who were crossed between 24 hours of bed rest and 24 hours of normal ward activity. Blood was taken at six hourly intervals and the results analysedby fitting sine waves with an assumed period of 24 hours to the measured concentrations $\frac{5}{\pi}$ Cytidine deaminase after activity, but not at rest, showed circadian variation, with a 24 hour mean level of 17.4 units (normal 3-13 units) and an amplitude of 1.1 units. The circadiarpo variation, defined as the curve's peak to trough difference as a percentage of the 24 hour mean: was $12.3 \%$ and occurred at 1208 hours. $\mathrm{C}$ reactive protein showed no significant circadiare rhythm, in keeping with published findings. The timing of the peak in serum cytidine deaminase concentrations after a period of morning physiotherapy, but not during the bedrest morning

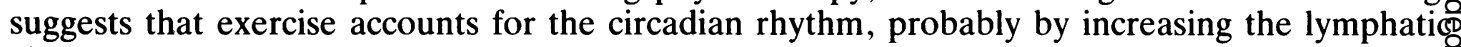
clearance from inflamed joints.

Key words: chronobiology, diurnal variation, nucleoside aminohydralase, joint inflammation.

It is not known why clinical measures of disease activity in rheumatoid arthritis (RA), such as grip strength, pain, stiffness, and articular index, show greatest activity in the early hours of the morning. ${ }^{12}$ Similar changes in blood total protein count, $\alpha_{1^{-}}$ antitrypsin, orosomucoid, caeruloplasmin, and transferrin ${ }^{2} 3$ suggest that there is diurnal variation of inflammatory markers, possibly related to circulating cortisol concentrations, though similar changes in $\mathrm{C}$ reactive protein (CRP), plasma viscosity, serum sulphydryl, and serum histidine have not been demonstrated..$^{2-4}$ Other factors may be importantfor example, diurnal variation in the erythrocyte sedimentation rate can be explained by food ingestion. ${ }^{5}$

Cytidine deaminase is a cytoplasmic enzyme found in high concentrations in polymorphs. It is

Accepted for publication 17 October 1988.

Correspondence to Dr P W Thompson, Bone and Joint Research Unit, The London Hospital Medical College, Turner Street, London E1 2AD. released from dead and damaged polymorphs in inflamed rheumatoid joints and drains down its. concentration gradient from synovial fluid to theo blood. $^{6}$ The serum concentration of cytidine deaminase reflects input from all inflamed joints. It응 is an integrated measure of joint inflammation that has been shown to correlate with existing measures of joint inflammation ${ }^{7}$ and to reflect longitudinalN changes in a patient's condition. ${ }^{8}$

This paper reports a study that was designed to assess circadian variation in serum cytidine deami- $\omega$ nase in a group of patients with RA studied at rest and during activity. CRP was also measured as ao control marker of inflammation known not to show circadian rhythm. ${ }^{2}$

\section{Patients and methods}

With ethical committee approval and written in- $-\frac{\overrightarrow{\mathbb{D}}}{\Omega}$ formed consent, eight female and three male in-o patients of mean age 62 years (range 40-71) with 
definite or classical $\mathrm{RA}^{9}$ volunteered for the study. Patients with infections or recent changes in treatment were excluded. Patients were randomly allocated to 24 hours' bedrest or normal ward activities on the first day, crossing to the other regimen for the second day. Blood was taken at $0600,1200,1800$, and 2400 on each day. During the rest day the patients stayed in bed but were allowed up to the toilet. During the activity day the patients were encouraged to get up after the 0600 venepuncture and attended physiotherapy during the morning.

Clotted blood samples were centrifuged at $1000 \mathrm{~g}$ for 10 minutes. One aliquot of serum was stored at $-20^{\circ} \mathrm{C}$ for cytidine deaminase estimation (carried out within one month of collection) and one aliquot at $4^{\circ} \mathrm{C}$ for CRP estimation. Cytidine deaminase was assayed by the method of Jones $e a^{10}$ and CRP by nephelometry. ${ }^{11}$

Data or data transformations (as logs and percentages of the 24 hour mean) were assessed by analysis of variance ${ }^{12}$ and by fitting sine curves with an

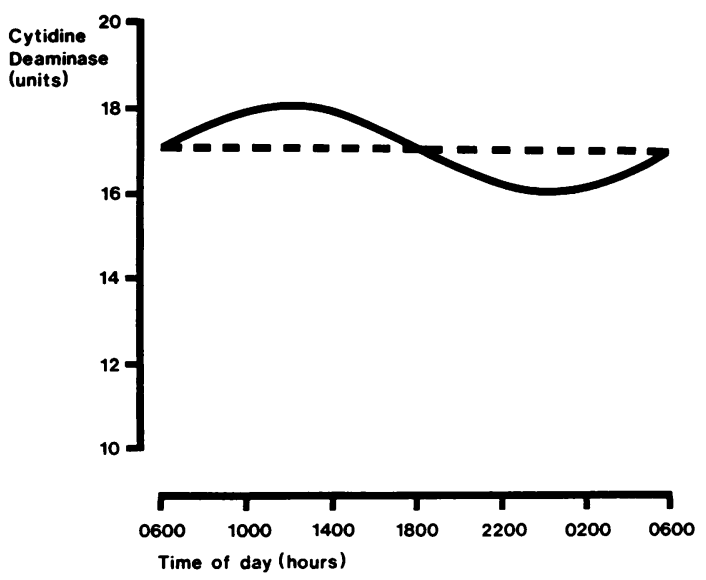

Fig. 1 Circadian rhythmicity of cytidine deaminase in 11 diurnally active patients with rheumatoid arthritis. assumed period of 24 hours by least squares regression techniques. ${ }^{13}$ The amplitude of the sine waves so derived was tested against zero-that is, with the null hypothesis that the data did not vary significantly with time of day. The interday differences were compared by Student's $t$ test.

\section{Results}

There was no significant circadian variation of CRP concentrations. Cytidine deaminase values after activity, but not at rest, showed circadian rhythm $(p=0.048)$ (Fig. 1) with a mesor (24 hour mean level) of 17.4 units and an amplitude of 1.1 units. The circadian variation, defined as the fitted curve's acrophase (peak) to bathyphase (trough) difference as a percentage of the 24 hour mean, was $12 \cdot 3 \%$. The acrophase occurred at 1208 and the bathyphase at 0008 .

There were no statistically significant interday differences for CRP (Table 1). The serum cytidine deaminase concentration was higher at 1200 on the exercise day than on the rest day $(p=0.048)$, but there were no other significant differences (Table 1).

\section{Discussion}

The results suggest that serum cytidine deaminase concentrations follow a circadian rhythm in ambulatory hospital inpatients with RA but not in patients resting in bed, whereas CRP shows no such variation, in keeping with published findings. ${ }^{23}$

A common pattern of change in human biological systems is a cycle repeated every 24 hours. One way of studying such circadian rhythms is by fitting a sine wave. The technique is useful in supplying the time of the maximum and minimum values, allowing comparison between rhythms, but may artificially reduce the amplitude of the variation and exclude other potential patterns. These possible short-

Table 1 Mean and standard deviation (SD) concentrations of cytidine deaminase and $C$ reactive protein in 11 inpatients with rheumatoid arthritis during 24 hours bed rest or 24 hours of normal ward activity

\begin{tabular}{|c|c|c|c|c|c|c|c|c|}
\hline \multirow[t]{3}{*}{ Time } & \multicolumn{4}{|c|}{$C$ reactive protein $(\mathrm{mg} / \mathrm{l})^{*}$} & \multicolumn{4}{|c|}{ Cytidine deaminase (units) $\dagger$} \\
\hline & \multicolumn{2}{|l|}{ Rest } & \multicolumn{2}{|c|}{ Exercise } & \multicolumn{2}{|l|}{ Rest } & \multicolumn{2}{|c|}{ Exercise } \\
\hline & Mean & $S D$ & Mean & $S D$ & Mean & $S D$ & Mean & $S D$ \\
\hline 0600 & $4 \cdot 4$ & $3 \cdot 6$ & $5 \cdot 0$ & $4 \cdot 1$ & $15 \cdot 1$ & $8 \cdot 3$ & $17 \cdot 0$ & $13 \cdot 1$ \\
\hline 1200 & $4 \cdot 4$ & $3 \cdot 7$ & $5 \cdot 5$ & $4 \cdot 9$ & $14 \cdot 5 \dagger$ & $6 \cdot 9$ & $18 \cdot 2$ & $10 \cdot 5$ \\
\hline 1800 & $4 \cdot 5$ & $4 \cdot 0$ & $5 \cdot 5$ & $4 \cdot 7$ & $15 \cdot 7$ & $6 \cdot 6$ & $17 \cdot 1$ & $8 \cdot 9$ \\
\hline 2400 & $4 \cdot 6$ & $4 \cdot 0$ & $5 \cdot 4$ & $4 \cdot 5$ & $16 \cdot 8$ & $8 \cdot 5$ & $16 \cdot 1$ & $7 \cdot 4$ \\
\hline
\end{tabular}

${ }^{*} \mathrm{C}$ reactive protein-normal range $0.8-8.0 \mathrm{mg} / \mathrm{l}$; cytidine deaminase-normal range $3-13$ units.

$+\mathrm{p}<0.05$ (paired $t$ test) compared with the exercise day. 
comings should be borne in mind when the interpretation of any chronobiological study is considered. ${ }^{14}$

Most workers attribute circadian rhythms in clinical and serological measures of inflammation to a cyclical variation in circulating cortisol concentrations that peak early in the morning. It has been suggested that the morning exacerbation of symptoms experienced by many patients with RA is related to these changes, ${ }^{15}$ though the definitive criteria for proof of a causal relation have never been met. ${ }^{16}$ The results presented here, however, suggest that exercise is an important factor in the diurnal variation of serum cytidine deaminase. In patients with RA there is a steep gradient between inflamed synovial fluid cytidine deaminase and serum cytidine deaminase (up to 20:1), ${ }^{6}$ suggesting that cytidine deaminase originates from joints and drains into the blood. Small proteins, such as cytidine deaminase, are cleared from joints via the synovial lymphatic system, and the lymphatic flow is powered mainly by joint motion. ${ }^{17}$ It follows that patients with RA would be expected to have higher concentrations of serum cytidine deaminase after exercise than while resting. The inpatients studied underwent a period of moderately vigorous physiotherapy between 0830 and 1000 but spent the rest of the day according to the ward routine, which involves little ambulatory activity. The peak in serum cytidine deaminase concentrations around noon, and the lack of circadian variation during either day for CRP, which originates from the liver and is therefore unaffected by joint motion, is in keeping with this hypothesis.

The number of circulating polymorphs shows a circadian rhythm with a peak in the early evening in resting patients with $\mathrm{RA}^{2}$ as well as in normal controls. ${ }^{14}$ The pattern of cytidine deaminase variation shown here does not reflect this cycle, suggesting that there is no exercise related alteration in the numbers of blood polymorphs undergoing lysis.

Although statistically significant, the cyclical differences in serum cytidine deaminase were small (mean difference between acrophase and bathyphase 2.2 units). In RA, in which serum cytidine deaminase concentrations up to 50 units (normal 3-13 units) are possible, these differences are unlikely to be clinically important. Workers studying small difference in serum cytidine deaminase concentrations, such as those produced by the withdrawal of non-steroidal anti-inflammatory drugs, ${ }^{8}$ should, however, endeavour to collect? samples under controlled conditions.

We thank the sister, staff, and patients of Hastings Ward, the London Hospital, Mile End. The CRP measurements were kindly undertaken by Dr M Lowdell, Department of Immunology, The London Hospital, Whitechapel.

\section{References}

1 Lee P, Baxter A, Dick W C, Webb J. An assessment of grip. $\vec{\circ}$ strength in rheumatoid arthritis. Scand J Rheumatol 1974; 3:ت 17-23.

2 Harkness J A L, Richter M B, Panayi G S, et al. Circadian variation in disease activity in rheumatoid arthritis. $\mathrm{Br}$ Med $\widetilde{\widetilde{T}}$ 1982; 284: 551-4.

3 Bruguerolle B, Bouvenot G, Arnaud C, et al. Rythmesö circadiens des proteines dites de l'inflammation chez sujet sain. Rev Rhum Mal Osteoartic 1986; 53: 313-6.

4 Sitton N G, Taggart A J, Dixon J S, Surrall K E, Bird H A. N Circadian variation in biochemical assessments used to monitoro rheumatoid arthritis. Ann Rheum Dis 1984; 43: 444-50.

5 Mallya R K, Berry H, Mace B E W, De Beer F C, Pepys M B.Diurnal variation of erythrocyte sedimentation rate related to feeding. Lancet 1982; i: 389-90.

6 Thompson P W, Jones D D, Currey H L F. Cytidine deaminase as a measure of acute inflammation in rheumatoid arthritis. Annc Rheum Dis 1986; 45: 9-14.

7 Thompson P W, Jones D D, Currey H L F. Serum cytidine deaminase as an integrated measure of acute joint inflammation. Br J Rheumatol 1986; 25: 97-8.

8 Thompson P W, Kirwan J R, Jones D D, Currey H L F. Serum cytidine deaminase levels after the withdrawal of non-steroidal anti-inflammatory treatment in rheumatoid arthritis. $A n n \stackrel{\circ}{\circ}$ Rheum Dis 1988; 47: 308-12.

9 A committee of the American Rheumatism Association. Diagnostic criteria for rheumatoid arthritis, 1958 revision. 윽 Arthritis Rheum 1959; 18: 49-51.

10 Jones D D, Roberts E L. Enzymes of DNA metabolism in? clinical diagnosis. 2nd ed. Aberystwyth: Chancery Publications, 1986.

11 Ritchie T F. A simple, direct and sensitive technique for the measurement of specific proteins in a dilute solution. J Lab Clin:Med 1967; 70: 512-7.

12 Snedecor G W, Cochrane W G. Statistical methods. 6th ed Ames, USA: Iowa State University Press, 1980: 258-67.

13 Nelson W, Tong Y L, Halberg F. Methods for cosinorrhythometry. Chronobiologia 1979; 6: 305-23.

14 Pownall R. Biological rhythms in cell-mediated immunity: their 윽 relevance in rheumatology. Br J Clin Pract [Symp Suppl] 1984; 33: $20-3$.

15 Unger A. Biological rhythms in the humoral immune system: their possible significance in rheumatology. Br J Clin Practo (Symp Suppl) 1984; 33: 24-7.

16 Pownall R, Knapp M, Maloney J D, Kowanko I C. Circadian N variations in disease activity and endogenous corticosteroids. In: Fehm H L, Graupe K, Kobberling J, eds. Glukokortokoide, Forschung und Therapie. Erlangen: Perimed Fachbuch, 1984. $168-77$.

17 Levick J R. Synovial fluid and trans-synovial flow in stationaryळ్ and moving joints. In: Helminen $\mathrm{H} \mathbf{J}$ et al, eds. Joint loadingbiology and health of articular structures. Potters Bar: Wright, 1987. 